\title{
Oral Health Related Knowledge and Behavior Among Secondary School Students in Jazan Region, Kingdom of Saudi Arabia
}

\author{
Ismail Abbas Darout, Ali Yehia Mubarky, Majed Ahmed Abduh \\ Department of Preventive Dental Sciences, Division of Periodontology, College of Dentistry, Jazan University, Jazan, Kingdom of Saudi \\ Arabia
}

\author{
Email address: \\ idarout1959@gmail.com (I. A. Darout) \\ ${ }^{*}$ Corresponding author
}

To cite this article:

Ismail Abbas Darout, Ali Yehia Mubarky, Majed Ahmed Abduh. Oral Health Related Knowledge and Behavior Among Secondary School Students in Jazan Region, Kingdom of Saudi Arabia. American Journal of Health Research. Vol. 4, No. 5, 2016, pp. $138-142$.

doi: 10.11648/j.ajhr.20160405.15

Received: August 28, 2016; Accepted: September 10, 2016; Published: September 29, 2016

\begin{abstract}
Introduction: Awareness of oral health and related behavior are essential for prevention of dental caries andperiodontal diseases. This study explores secondary school students in Jazan region, Kingdom of Saudi Arabia with the respect to frequency and quality of use and the socio-demographic distribution of oral health knowledge and behavior. Materials and methods: Five secondary schools ( 3 from urban and 2 from suburban) were selected to be involved in this study. Self-reported questionnaires were distributed randomly to be completed by the participants from each school after having read a consent letter. The data were processed and analyzed by means of the Statistical Package for Social Sciences (SPSS). Results: Totally, $64.1 \%$ males and $71.5 \%$ females scored highly on knowledge of caries. The corresponding rates regarding the knowledge of gingivitis were $50.3 \%$ males and $50 \%$ females respectively. Toothbrushing and the use of miswak $\leq 2$ times a day were confirmed by $83.7 \%$ males and $90 \%$ females and by $44.5 \%$ males and $40.3 \%$ females, respectively. The durations of toothbrushing and the use of miswak for $>2$ minutes were confirmed by $43 \%$ males and $58.8 \%$ females and by $69.9 \%$ males and 72.5 females, respectively. Conclusion: Awareness of oral health issues is high, but specific misconceptions exist. There is gender equality in knowledge and practice of oral hygiene and that miswak stick was equally used with toothbrush for oral hygiene among secondary school students in Jazan.
\end{abstract}

Keywords: Chewing Sticks, Knowledge, Manual Toothbrush, Miswak Sticks, Oral Hygiene

\section{Introduction}

It has been indicated that the pattern of oral diseases is rapidly changing at the global level.For instance, dental caries experience and poor gum conditions have been declined among young aged groups in the developed countries, $[1,2]$.These are observed in parallel with improved socio-demographic conditions of the population, changes in lifestyle and effective use of preventive oral health programs. In addition, evidence shows increased personal self-care practices in terms of tooth brushing, use of interdental remedies, dental attendance patterns and use of fluorides among these populations [3].Most people in the developed countries show great interest in oral hygiene. Evidence indicates that $16 \%$ to $80 \%$ of boys in 32 countries in Europe and North America practiced tooth brushing more than once daily, while girls reported better compliance $26 \%$ to $89 \%$ [ 4 , 5]. In contrast, studies in a number of developing countries have shown increasing oral health problems due to lack of implementation of preventive oral health programs $[6,7,8]$.

A study from Tanzania reported that $92 \%$ of children up to the age of 15 years did not brush their teeth every day [9]. In Saudi Arabia, $83 \%$ of school children used toothbrush for oral hygiene while $16 \%$ used miswak (chewing stick prepared from Salvadora persica) [10]. The Consensus Statement on Oral Hygiene states that tooth brushing and other mechanical procedures including chewing sticks are considered the most reliable means of controlling plaque, 
provided that the cleaning is sufficiently through and performed daily [11]. Little information is available online about oral hygiene practices among Secondary school students in Jazan region. The appropriate knowledge and behavior related to oral health of secondary school students will assist establishment of preventive oral health programs in the region. The aims of the present survey were to explore, secondary school students in Jazan region, Kingdom of Saudi Arabia with the respect to frequency and quality of use and the socio-demographic distribution of oral health knowledge and behavior among students.

\section{Materials and Methods}

The total study population of the suggested secondary schools was estimated 700 students and by using convenience sampling method 499 students were randomly selected to be involved in this study.

\subsection{Samples and Procedures}

Self-reported questionnaires were given to student representatives from each category of the school and asked to be distributed randomly to the participants. The participants joined the study after having read a consent letter and accepted to participate. Refusals were replaced by random distribution of new questionnaires.

\subsection{Survey Instrument}

The study involved distribution of a pre-coded questionnaire constructed in English by the authors The questionnaire contained 32 questions assessing sociodemographic characteristics and a number of variables related to knowledge of causes of oral diseases and means of their prevention, including tooth cleaning frequency and methods cleaning. Prior to the distribution of the questionnaire, the principal investigator explained to the participants the aims of the study, gave examples how to complete the questionnaire adequately and offered immediate assistance with the completion, if required.

\subsection{Measurements}

Gender was assessed as male/female; age was grouped into 15-17 years-old and $\geq 18$ years old. Frequency of tooth cleaning using toothbrush and/or miswak was measured as: less or equal to $\leq 2$ times a day to more than 2 times a day.Two dummy variables were constructed, yielding $\leq 2$ times a day, $>2$ times a day. Duration of tooth cleaning was assessed by asking "For how many minutes do you toothbrush/clean with miswak?" using a scale ranging from $\leq$ 2 minutes to $>2$ minutes. Two dummy variables were constructed yielding $\leq 2$ minutes and $>2$ minutes. Reason for using toothbrush and/or miswak was estimated using the categories better cleaning and other reasons; whereas method of tooth cleaning was measured using a scale rotation method and other methods. Having received information regarding tooth brushing/tooth cleaning was assessed as no or yes.
Moreover, the respondents were requested to evaluate the following five statements regarding causes of oral diseases in terms of yes/no/don't know: Caries can occur by: bad cleaning; not visiting a dentist; having weak teeth; having a worm in the tooth; consuming sugared foods.

A sum index of knowledge about caries was constructed (range 1-5) and reduced to a dummy variable high knowledge and low knowledge based on a median split. Using the same response scale students were requested to evaluate four statements about the causes of gingivitis: irregular tooth; brushing; having a virus in the gum; having bacteria in the gum; having a worm in the gum. A sum score of knowledge about gingivitis was constructed by adding the four items. This sum score was dichotomized based on a median split into high knowledge and low knowledge.

\subsection{Statistical Analysis}

The data were processed and analyzed by means of the Statistical Package for Social Sciences (SPSS version 20, Institute Inc., Cary, NC, USA). Frequency distributions of variables were computed separately for male and female students. Logistic regression analyses were conducted with knowledge scores and oral hygiene behavior as dependent variables. Contingency tables were made for sociodemographic variables. The Chi-square test was used for comparisons between males and females. Differences with a $\mathrm{p}<0.05$ were considered statistically significant.

\subsection{Ethical Considerations}

The study proposal was submitted to College of Dentistry Research and Publication Office for ethical clearance and written informed consent was obtained from the participants prior to study commencement. In this concern, it has been stated to the participants that there is no direct benefit of their participation in the study, however knowledge gained from the study may lead to the prevention and treatment of oral diseases (general population benefits) and about the confidentiality, that no information about the participants, or provided by them during the research will be disclosed to others without their written permission.

\section{Results}

\section{Oral Hygiene Practice}

The total participants were 499 students, 419 males and 80 females of these 300 students were from urban schools and 199 from suburban. Their ages were grouped into 15-17 years and more than 18 years. The results regarding percentage distribution and number of the study participants according to socio-demographic characteristics were summarized in table 1 . The knowledge items were divided into items of causes of caries and gingivitis. Totally, $64.1 \%$ males and $71.5 \%$ females scored highly on knowledge of caries. The corresponding rates regarding the knowledge of gingivitis were $50.3 \%$ and $50 \%$ respectively. Table 1 shows the percentage distribution (\%) and numbers (n) of the study 
participants who confirmed specific causes of dental caries and gingivitis.

Toothbrushing and the use of miswak $\leq 2$ times a day was confirmed by $83.7 \%$ males and $90 \%$ females and by $44.5 \%$ males and $40.3 \%$ females, respectively. The results showing percentage distribution and number of the study participants who confirmed specific causes of dental caries and gingivitis are summarized in Table 2. Duration of tooth brushing for more than 2 minutes was equally responded among males and females. Les half number of both males and females who used a toothbrush applied the horizontal and vertical methods. More than half of the toothbrush users gave "Good cleaning properties" as the major reason for such use Table 3. Substantial proportion of the males $(55.5 \%)$ and females (59.7.2\%) reported using miswak at least twice a day Table 4. A majority of males and fewer females gave other reasons in terms of pleasantness, tradition, religion and good prices for using miswak. Table 4 shows percentage distribution $\%$ and (n) number of the study participants according to frequency, duration, reason and method of brushing with miswak.

Table 1. Percentage distribution (\%) and numbers (n) of the study participant's socio-demographic characteristics in urban and suburban areas of Jazan region.

\begin{tabular}{lllll}
\hline $\begin{array}{l}\text { Socio- } \\
\text { demographic }\end{array}$ & \multicolumn{2}{l}{ Urban } & \multicolumn{3}{l}{ Suburban } \\
\hline Characteristics & \multicolumn{2}{l}{ Participants (n=300) } & \multicolumn{2}{l}{ Participants (n=199) } \\
\cline { 2 - 5 } \% & (n) & \% & (n) \\
\cline { 2 - 5 } Age (years) & 38 & 189 & 24.4 & 122 \\
$\begin{array}{l}15-17 \\
>18\end{array}$ & 22.2 & 111 & 15.4 & 77 \\
Gender & & & & \\
Females & 0.0 & 0.0 & 16 & 80 \\
Males & 60 & 300 & 23 & 119 \\
Father's education & & & & \\
Low education & 33 & 165 & 27 & 137 \\
$\begin{array}{l}\text { High education } \\
\text { Mother's education }\end{array}$ & 27 & 135 & 12 & 62 \\
$\begin{array}{l}\text { Low education } \\
\text { High education }\end{array}$ & 40 & 199 & 34 & 175 \\
\hline
\end{tabular}

Table 2. Percentage distribution (\%) and numbers (n) of the study participants who confirmed specific causes of dental caries and gingivitis.

\begin{tabular}{lllll}
\hline \multirow{2}{*}{ Knowledge items } & \multicolumn{2}{c}{ Males $(\mathbf{n}=\mathbf{4 1 9})$} & \multicolumn{2}{l}{ Females $(\mathbf{n}=\mathbf{8 0})$} \\
\cline { 2 - 5 }$(\%)$ & $(\mathrm{n})$ & $(\%)$ & $(\mathrm{n})$ \\
\hline $\begin{array}{l}\text { Causes of caries } \\
\text { Bad Cleaning }\end{array}$ & 76.6 & 321 & 80 & 64 \\
$\begin{array}{l}\text { Avoid visiting } \\
\text { dentist }\end{array}$ & 62.4 & 260 & 67.5 & 54 \\
$\begin{array}{l}\text { Having a week } \\
\text { teeth }\end{array}$ & 45.3 & 189 & 52.5 & 42 \\
$\begin{array}{l}\text { Microorganisms } \\
\begin{array}{l}\text { Sugared food } \\
\text { Causes of gingivitis }\end{array}\end{array}$ & 63 & 262 & 78.8 & 63 \\
$\begin{array}{l}\text { Irregular tooth } \\
\text { brushing }\end{array}$ & 75.4 & 281 & 78.8 & 63 \\
$\begin{array}{l}\text { A virus in the } \\
\text { mouth }\end{array}$ & 40.6 & 168 & 41.2 & 33 \\
$\begin{array}{l}\text { Bacteria in the } \\
\text { mouth }\end{array}$ & 48.9 & 203 & 51.2 & 41 \\
$\begin{array}{l}\text { Information on } \\
\text { brushing }\end{array}$ & 36.7 & 152 & 38.8 & 31 \\
\hline
\end{tabular}

Table 3. Percentages distribution (\%) and Numbers (n) of the study participants according to frequency, duration, reasons and method of brushing with toothbrush.

\begin{tabular}{lllll}
\hline \multirow{2}{*}{ Toothbrush } & \multicolumn{2}{c}{ Males $(\mathbf{n}=\mathbf{4 1 9})$} & \multicolumn{2}{c}{ Females $(\mathbf{n}=\mathbf{8 0})$} \\
\cline { 2 - 5 } & $\mathbf{( \% )}$ & $\mathbf{( n )}$ & $\mathbf{( \% )}$ & $\mathbf{( n )}$ \\
\hline $\begin{array}{l}\text { Brushing frequency } \\
\leq 2 \text { times a day }\end{array}$ & 83.7 & 350 & 90 & 72 \\
$>$ 2 times a day & 16.3 & 68 & 10 & 8 \\
$\begin{array}{l}\text { Bushing duration } \\
<2 \text { minutes }\end{array}$ & 57 & 239 & 41.2 & 33 \\
$>2$ minutes & 43 & 180 & 58.8 & 47 \\
$\begin{array}{l}\text { Brushing methods } \\
\text { Horizontal and }\end{array}$ & 30.1 & 126 & 27.5 & 22 \\
vertical & 32.7 & 137 & 43.8 & 35 \\
$\begin{array}{l}\text { Rotation } \\
\text { Just brushing }\end{array}$ & 37.2 & 156 & 28.8 & 23 \\
$\begin{array}{l}\text { Reason for using toothbrush } \\
\text { Better cleaning }\end{array}$ & 52.4 & 219 & 53.8 & \\
$\begin{array}{l}\text { Civilized method } \\
\text { Traditional }\end{array}$ & 22.7 & 95 & 20 & 16 \\
\hline
\end{tabular}

Table 4. Percentages distribution (\%) and Numbers (n) of the study participants according to frequency, duration, reasons and method of brushing with miswak.

\begin{tabular}{|c|c|c|c|c|}
\hline \multirow{2}{*}{ Miswak } & \multicolumn{2}{|c|}{ Males (n=419) } & \multicolumn{2}{|c|}{ Females $(\mathrm{n}=\mathbf{8 0})$} \\
\hline & $(\%)$ & (n) & $(\%)$ & (n) \\
\hline \multicolumn{5}{|c|}{ Brushing frequency } \\
\hline$\leq 2$ times a day & 44.5 & 181 & 40.3 & 31 \\
\hline$>2$ times a day & 55.5 & 226 & 59.7 & 46 \\
\hline \multicolumn{5}{|l|}{ Bushing duration } \\
\hline$<2$ minutes & 30.1 & 126 & 27.5 & 22 \\
\hline$>2$ minutes & 69.9 & 292 & 72.5 & 58 \\
\hline \multicolumn{5}{|c|}{ Brushing methods } \\
\hline $\begin{array}{l}\text { Horizontal and } \\
\text { vertical }\end{array}$ & 44 & 183 & 47.5 & 38 \\
\hline Just brushing & 56 & 233 & 52.5 & 42 \\
\hline \multicolumn{5}{|c|}{ Reason for using miswak } \\
\hline Better cleaning & 57.2 & 239 & 43 & 34 \\
\hline Better taste & 30.4 & 127 & 45.6 & 36 \\
\hline Traditional & 12.4 & 52 & 11.4 & 9 \\
\hline
\end{tabular}

\section{Discussion}

Epidemiological data regarding oral health knowledge and behavior of secondary schools students in Jazan region Kingdom of Saudi Arabia have not previously been published online. The present survey was undertaken together such information among them to aid the establishment of preventive oral health education programs. Thus, the participants of this study were selected because they were secondary school Students and we considered them as pool sample with equal knowledge in the field of oral health. The results presented in this study are considered to be representative for thestudents attending secondary schools in Jazan region. Our study shows that all students correctly completed the questionnaires which demonstrate keen interest of the students in their oral health matters.

Although misconceptions about oral health among the students still exist in the present study, a high proportion of boys and girls had correct knowledge, confirming for instance that inappropriate cleaning and consumption of sugared foods cause tooth decay and that gingivitis might be 
attributed to irregular tooth brushing. No significant differences were identified between boys and girls in our study concerning the single knowledge items. However, females are more often than males preferred "Avoid visiting a dentist" as a cause of dental caries [12]. Moreover, in a representative study of school children living in urban areas in Jordan, Rajab et al. [13] found no substantial differences between boys and girls in responses to oral health knowledge items. A study of secondary schools students in Khartoum Province indicated that there was gender equality in knowledge and practice of oral hygiene [12]. These observations may indicate that when both sexes are at identical educational levels, they are equally knowledgeable with respect to oral health issues.

Farsi et. al. [14]indicated that $87 \%$ of the school students in Jeddah City knew that regular toothbrushing can prevent gum diseases. The level of knowledge identified in our study schools was encouraging and may have implications for preventive oral health program. Thus, from a theoretical point of view, oral health habits are a function of perceived vulnerability to an oral disorder and the belief that a particular preventive measure will be sufficient to overcome this vulnerability. People who have assimilated oral health knowledge and feel a sense of personal control over their oral health are more likely to adopt self-care practices [15]. The finding of the present study demonstrated that a substantial proportion of the participants reported using toothpaste whereas most miswak, \{chewing stick prepared from a variety of plant stems and twigs, Wu et. al. [16]\}, users did not use any adjuvant. Toothbrushing with toothpaste is arguably the most common form of tooth cleaning practice by individuals in the industrialized countries, whereas the chewing stick is often used as the sole cleansing agent by individuals in developing countries. In this study, more and less than two thirds of the toothbrush and miswak users, respectively, cleaned their teeth at least twice a day. From Kuwait, it was recently concluded that the male Health Sciences College students seemed to have appropriate knowledge on some oral health topics, but limited knowledge on the others that their toothbrushing practices are still far behind the international recommendation (twice a day) and also the knowledge, why it should be done so frequently also very limited [17].

\section{Conclusion}

The study shows that awareness of oral health issues is high, but specific misconceptions exist and that there is gender equality in knowledge and practice of oral hygiene among secondary school students. Miswak stick was equally used with toothbrush for oral hygiene practice.

\section{Recommendations}

Based on our study findings we recommend establishment of preventive oral health program in Jazan University that addresses oral health promotion and disease prevention and that the notion of oral health as integral part of community health should be central to construction of such strategy

\section{Acknowledgments}

The authors thank the secondary students at the Jazan region, who participated in this study. We also thank final students, Ahmed Aarishi, Hassan Sharwani, for their participation in translation of the questionnaires. Thisstudy was facilitated by the College of Dentistry, Jazan University.

\section{References}

[1] Reich E. Trends in caries and periodontal health epidemiology in Europe. Int Dent J 2001; 51 (6):392-8.

[2] Brown LJ, Wall TP, Lazar V. Trends in total caries experience: permanent and primary teeth. J Am Dent Assoc 2000; 131 (2): 223-31.

[3] Bratthall D, Hansel-Petersson G, Sundberg H. Reasons for the caries decline: what do the experts believe? Eur J Oral Sci1996; 104 (4): 416-22.

[4] Maes L, Vereecken C, Vanobbergen J, Honkala S. Tooth brushing and social characteristics of families in 32 countries. Int Dent J 2006; 56 (3): 159-167.

[5] Kuusela S, Honkala E, Kannas L, Tynjälä J, Wold B. Oral hygiene habits of 11-year-old schoolchildren in 22 European countries and Canada in 1993/1994. J Dent Res 1997; 76 (9): 1602-1609.

[6] Petersen PE, Mzee MO. Oral health profile of schoolchildren, mothers and school teachers in Zanzibar. Community Dent Health 1998; 15 (4): 256-62.

[7] Mosha HJ, Ngilisho LA, Nkwera H et al. Oral health status and treatment needs in different age groups in two regions of Tanzania. Community Dent Oral Epidemiol 1994; 22 (5): 30710 .

[8] Jensen K, Kizito EK, Langebaek $\mathrm{J}$ et al. Dental caries, gingivitis, and oral hygiene among schoolchildren in Kampala, Uganda. Tanzania. Community Dent Oral Epidemiol1973; 1 (2): 74-83.

[9] Normark S, Mosha HJ. Knowledge, practices and dental health among rural Tanzania children. Afr Dent $J$ 1989; 3 (2): 24-33.

[10] al-Tamimi S, Petersen PE. Oral health situation of schoolchildren, mothers and schoolteachers in Saudi Arabia. Int Dent J 1998; 48 (3): 180-6.

[11] Loe H. Oral hygiene in the prevention of caries and periodontal disease. Int Dent J 2000; 50 (3):129-39.

[12] Darout I. A, Anne N. Åstrøm and Nils Skaug. Knowledge and behaviuor related to oral health among secondary schools students in Khartoum province, Sudan. IntDent J 2005; 55 (4): 224-30.

[13] RajabL. D, Petersen P. E.,Bakaeen G \&Hamdan M. A. Oral health behaviour of schoolchildren and parents in Jordan. Int $J$ Paediatr Dent 2002; 12 (3): 168-76. 
[14] Farsi JM, Farghaly MM, Farsi N. Oral health knowledge, attitude and behaviour among Saudi school students in Jeddah city. $J$ Dent 2004; 32 (1):47-53.

[15] Almas K, Al Shwaimi E, Al shamrani H, Skaug N. The oral hygiene habitis among intermediate and secondary schools students in Riyadh, Saudi Arabia. Pakistan Oral \& Dent $J$ 2003; 23: 29-34.
[16] Wu CD, Darout IA, Skaug N. Chewing sticks: timeless natural toothbrushes for oral cleansing. J Periodontal Res 2001; 36 (5): 275-84.

[17] Al-Ansari J, Honkala E, Honkala S. Oral health knowledge and behavior among male health sciences college students in Kuwait. BMC Oral Health 2003; 3 (1): 2. 